\title{
Optimization of sugar-free konjac gel texture containing erythritol-sucralose sweetener for producing healthy jam
}

\author{
*Akesowan, A. and Choonhahirun, A. \\ Department of Food Science and Technology, School of Science and Technology, University of the Thai \\ Chamber of Commerce, 126/1 Vibhavadee-Rangsit Road., Dindaeng, Bangkok 10400, Thailand
}

\begin{abstract}
Article history:
Received: 10 November 2018

Received in revised form: 4

January 2019

Accepted: 6 January 2019

Available Online: 15 January 2019
\end{abstract}

Keywords:

Gelled foods,

Konjac flour,

Textural characteristics,

Response surface

methodology,

Erythritol-sucralose

\section{DOI:}

https://doi.org/10.26656/fr.2017.3(3).139

\begin{abstract}
The understanding of textural characteristics of gels, which replace for sugar with sugar substitute, is essential for designing gel-based healthy food products. This research aimed to investigate the changes in textural characteristics as well as to optimize the gel condition of sugar-free konjac gel using the response surface methodology. A central composite rotatable design was implemented to determine the texture profile analysis, including the hardness, cohesiveness and springiness. Two independent variables, comprising different levels of konjac flour-to-xanthan ratio $(25: 75$ to $50: 50 \mathrm{w} / \mathrm{w})$ and erythritol-sucralose (ES) concentration $(0.2-2.5 \% \mathrm{w} / \mathrm{v})$, were studied. Konjac gels showed an increase in all textural characteristics when increasing the konjac content, while a slight change was induced by ES. The optimized konjac gel condition was tested for its characteristics and acceptability as pineapple jam, during the storage for 30 days at refrigerated temperature $\left(10-12^{\circ} \mathrm{C}\right)$. The low-sugar jam made with ES was acceptable and showed its overall acceptability score in a moderate preference. Both sucrose and ES jams were firmer and brighter during storage. After refrigeration for 30 days, both products showed lowered liking scores for some sensory attributes; however, they were microbiologically safe.
\end{abstract}

\section{Introduction}

The demand for foods that contribute to human health is still growing in a current society where most consumers get sick or health problems with their overconsumption of sugar and/or fat. Refined sugar, a common sweetener used to sweeten or flavor several food products, is reported as a risk factor leading to cause high blood pressure, obesity, diabetes, dental decay and metabolic syndrome (Sinchaipanit et al., 2013). In gelled foods category, in particular jams and jellies, sugar also performs as a part of the bulk, thereby it participates in the formation of structure and texture of the gels produced by hydrocolloids used in these products. Bayarri et al. (2006) reported that a kcarrageenan/locust bean gum mixed gel was stronger when sucrose was incorporated at up to $40 \%$ level. A similar result was found by Tiwari and Bhattacharya (2014), who noticed that the increase of sucrose content by added mango pulp made agar gels more rigid and cohesive. Hence, the change of gel texture is directly related to the proportions of sugar, and such a gel change by replacing sucrose with sugar substitutes is relevant to the consumer acceptance, especially texture and taste of food products (Vilela et al., 2015). Mosca et al. (2012) have described the relationship between gel texture and sensory perception from the perspective that the easier the gel is masticated into small fragments, the more the surface area contact between sweeteners and taste receptors occurs. Consequently, a softer gel provides a relatively higher taste intensity than that of a harder one.

Konjac flour or gum, a neutral linear glucomannan consisting of $\beta$ - $(1,4)$-mannose and glucose (1.6:1) structure, is derived from the tuber of Amorphophallus konjac C. Koch. It was approved for use as a thickening, gelling, stabilizing and texture-modifying agent in food products (Takigami, 2000). When the gum is dissolved in alkaline coagulants (e.g., calcium hydroxide or sodium carbonate), a thermally stable gel is formed, while a reversible gel is obtained by interacting the konjac with secondary or co-gelled gums ( $\kappa$-carrageenan, xanthan or gellan) (Huang and Lin, 2004). In general, konjac gel characteristics varied depending on the ratio of konjac and secondary gums, total concentrations, and quantity of sugar (Chua et al., 2010). As for its high soluble dietary fiber 'glucomannan', konjac has many healthpromoting benefits, namely it helps to reduce 
carbohydrate absorption, lower blood sugar, cholesterol and triglycerides, promote regular bowel movement, create a feeling of satiety or fullness, enhance weightloss effect, as well as provide a natural prebiotic (Chua et al., 2010; Delgado-Pando et al., 2011). Presently, popular konjac products are sold commercially, for example, fruit juice gels and jelly drinks, which are mostly sweetened with sugar. In this context, the health benefits obtained from konjac food products could be limited if formulated with sugar. As a consequence, a konjac-based food product without added sugar can be considered a healthy food choice for health-conscious consumers.

Most commercial sugar substitutes currently available are categorized into sugar alcohols and intense sweeteners, each with unique properties and effects in the food product in which they are used. The blend of sugar alcohol and intense sweetener is popularly used because it can overcome the limitations of individual sweeteners, improve taste and reduce cost (Souza et al., 2013). In this study, an erythritol-sucralose (ES) (98.6:1.4) mixed sweetener was chosen based on its many beneficial properties, including no contribution to tooth decay, 8-fold greater sweetness than sucrose, low caloric value $(0.18 \mathrm{kcal} / \mathrm{g})$, desirable sweet taste, bulking properties and improved cost availability (U-Sing Co. Ltd., 2012). The substitution of sucrose by sugar substitutes, which differ from sucrose in terms of used amounts, functional properties, sweetness perception, and bulking effect, can cause changes in product characteristics and sensorial perception. A comprehensive understanding of the texture changes of konjac/xanthan gels sweetened with ES, which can be determined by texture analysis and sensory evaluation, may assist in designing desirable healthy konjac-based food formulations. Response surface methodology (RSM) was selected to determine how the variables and their interactions affect the responses, as well as to identify the optimal processing conditions and formulations (Anderson and Whitcomb, 2005).

This study investigated the changes in the texture of konjac gels made with different ratios of konjac and xanthan $(25: 75$ to $50: 50 \mathrm{w} / \mathrm{w})$ and the ES concentration $(0.25-2.5 \% \mathrm{w} / \mathrm{v})$, using RSM. The optimal konjac gel condition was applied to create the no sugar added, pineapple jam, and its physical and sensory characteristics during storage were evaluated.

\section{Materials and methods}

\subsection{Materials}

Konjac flour (Chengdu Newstar Chengming BioTech Co., Ltd., Chengdu, China), xanthan gum
(Keltrol®; CP Kelco, San Diego, CA, USA), sucrose (Carlo Erba Reagenti, Rodano, Italy) and ES (U-Sing Co., Ltd., Bangkok Noi, Thailand) were used. Pineapple (Ananas comosus) was purchased from a local supermarket.

\subsection{Experimental design}

Two variables with five level combinations, coded $1.41,-1,0,1$ and 1.41 , were conducted on a central composite rotatable design (CCRD). The total proportion of the konjac/xanthan solutions was studied at $1 \%(\mathrm{w} / \mathrm{v})$. The ratio of konjac in the konjac/xanthan blend and the concentration of ES are presented in Table 1. The design of the experiments can be described by the mathematical model shown in Equation 1:

$Y=b_{0}+b_{1} X_{1}+b_{2} X_{2}+b_{11} X_{1}^{2}+b_{22} X_{2}^{2}+b_{12} X_{1} X_{2}$

where $\mathrm{Y}$ is the response calculated by the model; $\mathrm{X}_{1}$ and $\mathrm{X}_{2}$ are the coded konjac proportions for the konjac/ xanthan blend and ES, respectively; $b_{1}$ and $b_{2}$ are the linear coefficients for $X_{1}$ and $X_{2}$, respectively; $b_{11}$ and $b_{22}$ are the quadratic coefficients for $\mathrm{X}_{1}$ and $\mathrm{X}_{2}$, respectively; and $b_{12}$ is the interaction coefficient (Anderson and Whitcomb, 2005).

\subsection{Gel preparation}

The relevant amounts of konjac flour and xanthan gum were mixed gradually with distilled water and stirred with a magnetic stirrer for 10 mins. The mixture was heated in a water bath at $90 \pm 2^{\circ} \mathrm{C}$ for 10 mins, and then the ES was added, followed by continuous stirring for 20 mins. The hot mixture was poured into gel cups (3 $\mathrm{cm}$ diameter $\times 2.5 \mathrm{~cm}$ height) and cooled before refrigerating $\left(10 \pm 2^{\circ} \mathrm{C}\right)$ for $24 \mathrm{~h}$.

\subsection{Texture profile analysis (TPA) measurement}

The konjac gels were left in a room at $23 \pm 1{ }^{\circ} \mathrm{C}$ for 2 hrs, prior to removal from the cups. The TPA (hardness, cohesiveness and springiness) was determined using a texture analyzer (LRX Plus, Lloyd Instruments, Hampshire, UK), and the measurements analyzed using Nexygen ${ }^{\circledR}$ software with operating at $200 \mathrm{~mm} / \mathrm{min}$ crosshead speed and $50 \%$ strain.

\subsection{Pineapple konjac jam preparation}

A recommended ratio of konjac/xanthan solution (1 $\mathrm{g} / 100 \mathrm{~mL}$ ) was heated in a water bath at $90 \pm 2^{\circ} \mathrm{C}$ for 5 mins, with constant mixing. Pineapple pieces $(20 \mathrm{~g})$ were added and continued heating for 15 mins. The sweetener (sucrose or ES) was added next, followed by citric acid $(1 \mathrm{~g})$, and then heated for 5 mins. Next, it was poured into a hermetically sealed jar and stored in a refrigerator $\left(10-12^{\circ} \mathrm{C}\right)$ before evaluation. 


\subsection{Physical analysis}

A $5 \mathrm{~g}$ sample was blended with $50 \mathrm{~mL}$ of distilled water for $1 \mathrm{~min}$. The $\mathrm{pH}$ was measured using a $\mathrm{pH}$ meter (Model 320, Metler-Toledo Ltd., Essex, UK). Titratable acidity was determined according to the AOAC method (1990). Hunter color scales, $L^{*}(0=$ black, $100=$ white $)$, $\mathrm{a}^{*}(+=$ red, $-=$ green $)$ and $\mathrm{b}^{*}(+=$ yellow, $-=$ blue $)$, were measured by a HunterLab digital colorimeter (ColorFlex, Hunter Associates Laboratory, Reston, VA, USA). Firmness (N) was determined using a Lloyd texture analyzer equipped with a puncture probe (1.25$\mathrm{cm}$ diameter). The sample was compressed (crosshead speed at $250 \mathrm{~mm} / \mathrm{min}$ ) up to $50 \%$ of the original height.

\subsection{Storage stability of jams}

Both sucrose and ES jams were kept in a refrigerator, and physical, sensory and microbiological analysis was conducted after 0,15 , and 30 days of storage.

\subsection{Sensory evaluation}

The sensory test was conducted on the attributes of color, taste, texture, spreadability and overall acceptance, using a 9-point hedonic scale $(1=$ extremely dislike, $9=$ extremely like). Sixty untrained panelists (age between 18-50 years), who regularly consume jam, were recruited from the University of the Thai Chamber of Commerce, Thailand. Panelists were instructed to rinse their palates before testing each sample.

\subsection{Microbiological determination}

The sample was aseptically weighed and determined for total plate count and yeast and mold count according to the American Public Health Association for foodstuff examination (APHA, 2001). The media and incubation condition was used as follows: (a) PetrifilmTM Total
Plate Count: $35 \pm 2^{\circ} \mathrm{C}$ for $1-2$ days and (b) PetrifilmTM Yeast and Mold Count: $25 \pm 2^{\circ} \mathrm{C}$ for $3-5$ days. The microbial counts were expressed as $\log \mathrm{CFU} / \mathrm{g}$.

\subsection{Statistical analysis}

All analyzes were conducted in triplicate. TPA data were analyzed by analysis of variance (ANOVA), and multiple regression was performed using DesignExpert ${ }^{\circledR}$ Educational version 8.0.2 (State-Ease, Inc., Minneapolis, MN, USA). Physical and sensory data were statistically assessed by ANOVA using SPSS for Windows version 17.0. Treatment means were compared using Duncan's new multiple range test (Cochran and Cox, 1992).

\section{Results and discussion}

\subsection{Model evaluation}

Data collected for the TPA of the gels prepared with different levels of konjac/xanthan ratio and ES concentration (Table 1) were analyzed for the regression coefficients and subjected to ANOVA. The statistical results detailed that the konjac gels containing ES had high coefficients of determination $\left(\mathrm{R}^{2}\right)$, ranging between 0.8834-0.9559 (Equations 2-4). In consistent with these data, none of the models showed significant lack of fit values, indicating that the models developed to represent the response variables were accurate and reliable. The significant texture models are described as below:

$$
\begin{aligned}
& \text { Hardness }=13.22-0.41 \mathrm{X} 1 * * *+6.68 \mathrm{E}-003 \mathrm{X} 12^{*} \\
& (\mathrm{R} 2=0.9314) \\
& \text { Cohesiveness }=-0.10+0.03 \mathrm{X} 1 * *+0.10 \mathrm{X} 2^{*}- \\
& 4.07 \mathrm{E}-004 \mathrm{X} 12 * * *-0.02 \mathrm{X} 22^{* *}(\mathrm{R} 2=0.9559) \\
& \text { Springiness }=2.16+0.12 \mathrm{X} 1^{* *}+0.47 \mathrm{X} 2^{*}- \\
& 1.37 \mathrm{E}-003 \mathrm{X} 12 * *(\mathrm{R} 2=0.8834)
\end{aligned}
$$

\begin{tabular}{|c|c|c|c|c|c|}
\hline \multirow{2}{*}{ Run } & \multicolumn{2}{|c|}{ Coded variables (actual value) ${ }^{1)}$} & \multirow{2}{*}{ Hardness } & \multirow{2}{*}{ Cohesiveness } & \multirow{2}{*}{ Springiness } \\
\hline & $\mathrm{X}_{1}$ & $\mathrm{X}_{2}$ & & & \\
\hline 1 & $-1(28.66)$ & $-1(0.59)$ & 6.53 & 0.47 & 4.70 \\
\hline 2 & $1(46.34)$ & $-1(0.59)$ & 8.59 & 0.46 & 5.01 \\
\hline 3 & $-1(28.66)$ & $1(2.17)$ & 6.02 & 0.47 & 5.00 \\
\hline 4 & $1(46.34)$ & $1(2.17)$ & 9.23 & 0.43 & 5.15 \\
\hline 5 & $-1.41(25)$ & $0(1.38)$ & 5.79 & 0.47 & 4.77 \\
\hline 6 & $1.41(50)$ & $0(1.38)$ & 9.68 & 0.42 & 5.12 \\
\hline 7 & $0(37.5)$ & $-1.41(0.25)$ & 7.16 & 0.50 & 5.01 \\
\hline 8 & $0(37.5)$ & $1.41(2.5)$ & 7.14 & 0.47 & 5.18 \\
\hline 9 & $0(37.5)$ & $0(1.38)$ & 7.31 & 0.50 & 5.17 \\
\hline 10 & $0(37.5)$ & $0(1.38)$ & 7.40 & 0.50 & 5.15 \\
\hline 11 & $0(37.5)$ & $0(1.38)$ & 6.45 & 0.50 & 5.18 \\
\hline 12 & $0(37.5)$ & $0(1.38)$ & 6.40 & 0.50 & 5.17 \\
\hline 13 & $0(37.5)$ & $0(1.38)$ & 6.27 & 0.52 & 5.00 \\
\hline
\end{tabular}

Table 1. Independent coded variables with actual values and TPA results of konjac/xanthan gels containing ES.

1) $\mathrm{X}_{1}=\%(\mathrm{w} / \mathrm{w})$ konjac flour in konjac/xanthan blend and $\mathrm{X}_{2}=\%(\mathrm{w} / \mathrm{v})$ erythritol-sucralose. 
Where $\mathrm{X}_{1}=$ konjac proportion in the konjac/xanthan blend (\%), and $\mathrm{X}_{2}=\mathrm{ES}$ concentration (\%). *Significant at $\mathrm{p}<0.05 ; * *$ significant at $\mathrm{p}<0.01 ; * * *$ significant at $\mathrm{p}<0.001$.

\subsection{Textural properties of konjac gels containing ES}

The different levels of konjac/xanthan blend and ES concentration showed linear and quadratic, but no interaction effects on the TPA of the konjac gels (Equations 2-4). To better visualize the results, the RSM graphs were constructed (Figure 1). Regarding the Eq.2, the konjac/xanthan blend was the only variable that significantly affected the gel hardness. The increasing konjac/xanthan ratio from $25: 75$ to $50: 50$ revealed a quadratic increase in gel hardness, while the 0.25 to $2.5 \%$ ES addition, as equivalently sweet as 2 to $20 \%$ sucrose concentration, showed no significant effect $(p>0.05)$ (Figure 1a). Higher konjac content increases the synergistic interactions between konjac and xanthan molecules to form a six-fold helix intermolecular association, resulting in an ordered three-dimensional network or harder gel structure (Chandrasekaran et al., 2003; Agoub et al., 2007; Fitzpatrick et al., 2013). In gelled food products, sucrose also contributes to a complex structural functionality besides sweet tasting, possibly due to its bulking effect. This influences the condition of gelation and the characteristics of konjac gel texture. The ability of sucrose to compete with xanthan molecules for available water, the interaction between sucrose and water, and the proportion of konjac in the mixed gums blend could be related to the gel rigidity. Although erythritol has a similar bulking to sucrose, the use of ES blend is too small to affect the konjac gel structure. This behavior might be of considerable importance in producing konjac gels sweetened with sucrose, but not found in that with ES. In concurrence with this finding, Bayarri et al. (2006) reported that a low amount of aspartame addition showed no significant changes in textural compression parameters of a kcarrageenan gel, gellan gel and k-carrageenan/locust bean gum mixed gel. This observation suggests that the texture quality of konjac gels containing ES is primarily based on the proportion of konjac and xanthan, regardless of the level of ES used. Figure 1a reveals the greatest hardness was found when proportions of $50 \%$ konjac and any concentrations of 0.2 to $2.5 \%$ ES were used.

According to Equation 3, the variation of konjac proportion greatly affects the cohesiveness of konjac gels than ES concentration. A curvilinear graph in Figure 1b shows that there is a stronger increase in cohesiveness when the konjac proportion was increased from 25 to $45 \%$ in the mixed gum blend. Ahead of this level, the gel
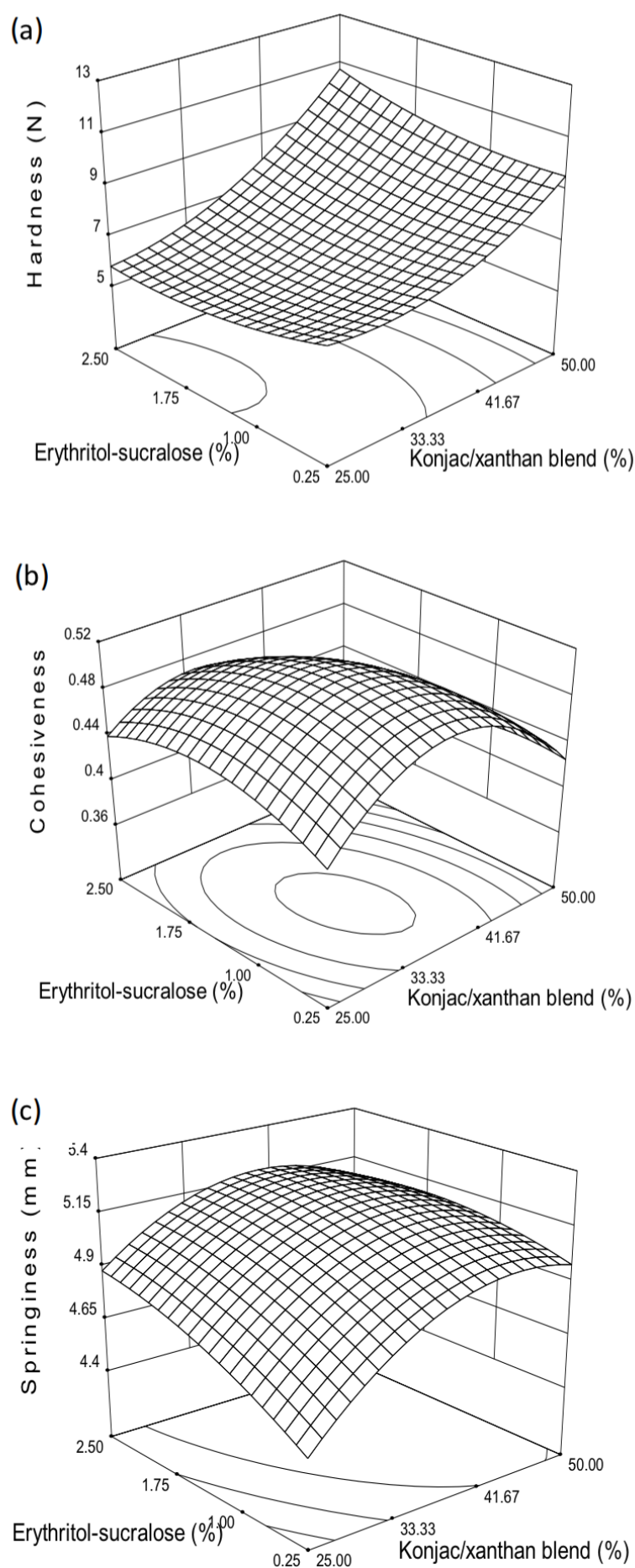

Figure 1. Response surface TPA graphs of konjac/xanthan gels containing ES: (a) hardness, (b) cohesiveness, and (c) springiness

cohesiveness tended to decrease. Higher konjac content increased the chance for konjac and xanthan molecules to interact together contributing to a more cohesive mixed gel. The graph also suggested the ratio of konjac and xanthan at 45:55 for the highest gel cohesiveness. Excessive amount of konjac flour $(>45 \%)$ might cause greater konjac islands (ungelled konjac), which is related to an increased viscosity of the gel system that slowed down the movement of konjac and xanthan molecular chains. This phenomenon might affect the threedimensional network between konjac and xanthan 
Table 2. Physical, sensory and microbial properties of konjac jams prepared with sucrose and ES during refrigerated storage.

\begin{tabular}{|c|c|c|c|c|c|c|}
\hline \multirow{3}{*}{ Characteristics } & \multicolumn{6}{|c|}{ Storage time } \\
\hline & \multicolumn{2}{|c|}{ Day 0} & \multicolumn{2}{|c|}{ Day 15} & \multicolumn{2}{|c|}{ Day 30} \\
\hline & Sucrose & ES & Sucrose & ES & Sucrose & ES \\
\hline \multicolumn{7}{|l|}{ Physical analysis } \\
\hline $\mathrm{pH}$ & $3.37 \pm 0.06^{\mathrm{aA}}$ & $3.40 \pm 0.05^{\mathrm{aA}}$ & $3.32 \pm 0.00^{\mathrm{aA}}$ & $3.38 \pm 0.03^{\mathrm{aA}}$ & $3.15 \pm 0.02^{\mathrm{bB}}$ & $3.29 \pm 0.04^{\mathrm{aB}}$ \\
\hline Titratable acidity (\%) & $1.46 \pm 0.12^{\mathrm{aB}}$ & $1.41 \pm 0.09^{\mathrm{aB}}$ & $1.50 \pm 0.15^{\mathrm{aB}}$ & $1.44 \pm 0.11^{\mathrm{aB}}$ & $1.61 \pm 0.11^{\mathrm{aA}}$ & $1.50 \pm 0.13^{\mathrm{bA}}$ \\
\hline Firmness $(\mathrm{N})$ & $1.45 \pm 0.04^{\mathrm{bA}}$ & $2.28 \pm 0.05^{\mathrm{aA}}$ & $5.78 \pm 0.32^{\mathrm{bB}}$ & $6.69 \pm 0.26^{\mathrm{aB}}$ & $6.85 \pm 0.45^{\mathrm{bC}}$ & $7.32 \pm 0.38^{\mathrm{aC}}$ \\
\hline$L^{*}$ value & $55.48 \pm 0.64^{\mathrm{bA}}$ & $57.95 \pm 0.45^{\mathrm{aA}}$ & $52.19 \pm 0.87^{\mathrm{bB}}$ & $56.02 \pm 0.49^{\mathrm{aB}}$ & $50.31 \pm 0.34^{\mathrm{bC}}$ & $54.76 \pm 0.61^{\mathrm{aC}}$ \\
\hline$a^{*}$ value & $-4.81 \pm 0.35^{\mathrm{bA}}$ & $-3.65 \pm 0.38^{\mathrm{aA}}$ & $-3.72 \pm 0.32^{\mathrm{bB}}$ & $-2.85 \pm 0.52^{\mathrm{aB}}$ & $-3.36 \pm 0.28^{\mathrm{bB}}$ & $-2.74 \pm 0.28^{\mathrm{aB}}$ \\
\hline$b^{*}$ value & $52.86 \pm 0.41^{\mathrm{aA}}$ & $51.18 \pm 0.24^{\mathrm{bA}}$ & $50.22 \pm 0.28^{\mathrm{aB}}$ & $47.75 \pm 0.32^{\mathrm{bB}}$ & $48.67 \pm 0.35^{\mathrm{aB}}$ & $46.95 \pm 0.17^{\mathrm{bB}}$ \\
\hline \multicolumn{7}{|l|}{ Sensory evaluation } \\
\hline Color & $7.5 \pm 0.4^{\mathrm{aA}}$ & $7.1 \pm 0.5^{\mathrm{bA}}$ & $7.4 \pm 0.1^{\mathrm{aA}}$ & $7.0 \pm 0.3^{\mathrm{bA}}$ & $7.0 \pm 0.5^{\mathrm{aB}}$ & $6.7 \pm 0.6^{\mathrm{bB}}$ \\
\hline Taste & $7.6 \pm 0.3^{\mathrm{aA}}$ & $6.3 \pm 0.4^{\mathrm{bA}}$ & $7.4 \pm 0.2^{\mathrm{aA}}$ & $6.4 \pm 0.5^{\mathrm{bA}}$ & $7.3 \pm 0.2^{\mathrm{aA}}$ & $6.5 \pm 0.2^{\mathrm{bA}}$ \\
\hline Texture & $7.1 \pm 0.6^{\mathrm{bA}}$ & $7.6 \pm 0.5^{\mathrm{aA}}$ & $6.9 \pm 0.7^{\mathrm{bA}}$ & $7.3 \pm 0.6^{\mathrm{aA}}$ & $6.6 \pm 0.4^{\mathrm{bB}}$ & $7.0 \pm 0.3^{\mathrm{aB}}$ \\
\hline Spreadability & $7.6 \pm 0.8^{\mathrm{aA}}$ & $7.2 \pm 0.4^{\mathrm{bA}}$ & $7.4 \pm 0.4^{\mathrm{aA}}$ & $7.0 \pm 0.5^{\mathrm{bA}}$ & $7.0 \pm 0.5^{\mathrm{aB}}$ & $6.7 \pm 0.3^{\mathrm{bB}}$ \\
\hline Overall acceptability & $7.4 \pm 0.3^{\mathrm{aA}}$ & $7.0 \pm 0.4^{\mathrm{bA}}$ & $7.4 \pm 0.5^{\mathrm{aA}}$ & $7.1 \pm 0.2^{\mathrm{bA}}$ & $7.1 \pm 0.4^{\mathrm{aB}}$ & $6.7 \pm 0.6^{\mathrm{bB}}$ \\
\hline \multicolumn{7}{|c|}{ Microbiological determination (Log CFU/g) } \\
\hline Total plate count & ND & ND & ND & ND & $<1$ & ND \\
\hline Yeast and molds & ND & ND & ND & ND & $<1$ & $<1$ \\
\hline
\end{tabular}

Mean in the same row with different superscripts are significantly different $(\mathrm{p}<0.05)$. ${ }^{\text {A-B }}$ Different capital letters significantly differed regarding storage time and ${ }^{a-b}$ different lower-case letters significantly differed regarding formulation, ND = not detected.

molecules, thereby lowering the gel cohesiveness. It was noticed that there was a slight change in the cohesiveness of konjac gels formulated with different quantities of ES.

The change in springiness varied greatly following the proportion of konjac in the mixed gums blend, while ES concentration showed a slight effect (Equation 4 and Figure 1c). The gel strength was consistent with observations regarding its springiness. The large proportion of konjac resulted in greater konjac-xanthan interactions, in association with the increase of hydrogen bonds between the konjac molecules, which might be the reason for increasing springiness (Huang and Lin, 2004). It was notable that, at low konjac proportion levels (25$30 \%$ ), high ES concentration showed a significant increase in springiness, which might be due to the water binding capacity of inherent erythritol that could retain neighboring water molecules to support for the intermolecular association between konjac and xanthan (Fitzpatrick et al., 2013). However, a comprehensive understanding is needed for further investigation.

\subsection{Optimization}

The gel condition designed to have maximized the highest hardness was optimized using Design-Expert ${ }^{\circledR}$ software. The corresponding gel was found to be the $1 \%$ konjac/xanthan (50:50) blend with $2.5 \%$ ES, which showed an overall desirability value of 0.93 . The value close to 1.0 (very desirable) means adequate levels of konjac/xanthan blend and ES are present for the textural quality of the konjac gel.

\subsection{Physical properties of konjac jams during storage}

Physical results of the low-sugar, pineapple konjac jam, formulated by the optimal konjac gel condition ( $1 \%$ konjac/xanthan (50:50) blend with 2.5\% ES) and the control jam sweetened with $16 \%$ sucrose are shown in Table 2. Changes in product formulation and storage time significantly affected $(p<0.05)$ firmness and color $\left(L^{*}, a^{*}\right.$ and $\left.b^{*}\right)$ of both jams. Although both jams showed no significant differences in $\mathrm{pH}$ and titratable acidity during 15 days of storage, at the end of storage for 30 days, the rate of decrease in $\mathrm{pH}$ and increase in titratable acidity was higher $(\mathrm{p}<0.05)$ in sucrose jam than ES jam. It was agreed with Pavlova et al. (2013) who reported the decrease in $\mathrm{pH}$ and increase in acidity of raspberry and peach jams stored for 15 and 90 days. Similarly, Roy et al. (2018) for similar results of carrot jams stored at room temperature for 90 days. This outcome might have been influenced by increasing of weakly ionized acids concentration, by the oxidation of reducing sugars to carboxylic acids, and ascorbic acids to dehydroascorbic acids and 2,3-diketogulonic acids (Benmeziane et al., 2018). Hence, the high sugar content in sucrose jam caused greater changes in $\mathrm{pH}$ and titratable acidity, relative to ES jam. The lower gel firmness was evident $(p<0.05)$ in sucrose jam, possibly due to the high water competition of sucrose compared to that of ES. As a result, the solubility of konjac and xanthan was interrupted by the presence of sucrose, which affected the interactions of konjac and xanthan molecules, leading to weaker junction zones in konjac- 
xanthan gel networks. In comparison with the sucrose jam, the ES one had a higher $L^{*}$, but lower $-a^{*}$ and $b^{*}$ values throughout storage, indicating that it was brighter. The increased color lightness might be due to ES is unable to participate in the Maillard reaction, a chemical reaction between reducing sugars and amine compounds that forms melanoidins (brown pigments), and typically happens in sucrose-containing foods (Alais and Linden, 1991). In the current study, although the ES jam was prepared without added sucrose, the jam contained some sugars originating from the pineapple pieces, and thus some Maillard reaction had occurred.

After storage for up to 30 days, it was evident that both jams had increased firmness, and lowered $\mathrm{L}^{*}$, -a* and $b^{*}$ values (Table 2), suggesting that the jams had become firmer and darker. During storage, progressive konjac-xanthan interactions may have caused the formation of the more extended junction zones through hydrogen bonding, thus increasing the gel firmness. Both jams turned brown at 30 days of storage, which might be a result of the Maillard reaction. The reduction in $\mathrm{L}^{*}$ value of sucrose jam was greater than that of ES, because of the higher sucrose content participating in the Maillard reaction.

It can be inferred that the different physical properties of both jams originated from the difference in their matrix composition. The sucrose replacement by ES causes a modification of jam composition, which influences the interactions of the matrix constituents and consequently, the quality of the product.

\subsection{Sensory evaluation of konjac jams during storage}

Sensory results presented in Table 2 show that sucrose jam had significantly $(\mathrm{p}<0.05)$ higher scores for color, taste, spreadability and overall acceptability, whereas, ES jam showed a higher $(\mathrm{p}<0.05)$ texture score. These data indicated that the different quantities and functional properties between ES and sucrose might influence the product characteristics and sensorial acceptance. At day 0 (after processing), most panelists preferred and gave the higher color scores to the sucrose jam, which showed more intense color than the ES jam. This result was consistent with the instrumental color (lower L* values) data in Table 2. As expected, ES jam showed a lower taste score than sucrose sample, which might be due to the panelists were not accustomed to the sweet taste of this ES. According to Souza et al. (2013), the sweetness perception of a sweetener varies depending on several factors, such as the type and concentration, individual sweetness profile, dispersing medium, familiarity, temperature and $\mathrm{pH}$. Additionally, the difference in gel hardness has been reported for its effect on sweetness perception. Mosca et al. (2012) stated that a softer gel was more easily masticated into small fragments, and this increased the contact surface area between the sweetener and taste receptors, leading to higher perceived taste intensities compared to a harder gel. This might be supportive of the reason why panelists preferred sweet taste of sucrose jam (softer gel) to the ES jam (harder gel). The panelists rated the texture of ES jam a higher score, indicating that they liked this jam consistency over that containing sucrose. It implies that the way the firmer gel of ES jam breaks down in the mouth (mastication) leads to higher texture perception as compared to the softer gel in the sucrose jam. The change in sucrose gel characteristics, which influenced the rheological properties of the jam, might come from several factors such as $\mathrm{pH}$, acidity, sugar or sweeteners, and gelling agents, such as konjac and xanthan gums (Benmeziane et al., 2018). Spreadability, expressed as an ability to spread the jam on a toast, is described as a key characteristic influencing consumer acceptance of jam products. The sucrose jam had higher score of spreadability, possibly because of its weaker gel strength; hence, it was easier to spread than the ES jam. As previously mentioned, sucrose increases the soluble solids content and water holding capacity of the gel system, thus thickening the dispersing medium. This might be caused the gel to be softer due to the restricted hydration of konjac and xanthan, specific sucrose-konjac or sucrose-xanthan interactions, a reduced number of water molecules participating in the molecular chains of the gum, or changes in water structure (Knecht, 1990; Sharma et al., 2009). Among all the sensory attributes assessed, the taste was the most affected, which decreased remarkably $(p<0.05)$ in the ES jam relative to the sucrose one. With higher scores for taste and spreadability, after processing (day 0), sucrose jam had an overall acceptability score of 7.4, which was significantly higher $(\mathrm{p}<0.05)$ than ES jam, which scored 7.0. Nonetheless, it indicated that ES could be used as a sweetener in this formulation because the low-sugar jam had good sensory acceptance, corresponding to the 'liked moderately' level.

After refrigerated storage for 15 days, there were no significant differences in all sensory attributes between both jams. At 30 days storage, both jams were scored lowered $(\mathrm{p}<0.05)$ for color, texture, spreadability and overall acceptability than their fresh $(0$ days $)$ counterparts, but not for taste ( $p>0.05)$. Additionally, the sucrose jam tended to darker tonality because of its higher sucrose content than ES jam.

Microbiological results (Table 2) presented almost nil total plate count, yeast and molds in both jams during refrigerated storage. Commonly, the jam with less sugar is more susceptible to microbial growth than the regular 
jam. However, jam with ES contained less sugar was microbiological safe for 30 days of storage, which was attributed to packaging the product in hermetically sealed jars and the low storage temperature.

\section{Conclusion}

The RSM test effectively explained the changes in konjac gel characteristics, showing increases in hardness, cohesiveness and springiness with increasing konjac proportions in konjac/xanthan blend from 25:75 to 50:50, while ES concentration showed a slight effect. The optimized condition for konjac gel was achieved using a $1 \%$ konjac-to-xanthan (50:50) ratio with $2.5 \%$ ES. The ES jam was relatively firmer, brighter, and less accepted than the sucrose jam. However, the ES jam was rated for an overall acceptability score of 7.0, which corresponded to a moderate sensorial preference, suggesting a feasible use of ES as sucrose replacement. Besides, both jams darkened and thickened during storage, but remained microbiologically safe for 30 days under refrigerated conditions.

\section{Conflict of Interest}

The authors declare no conflict of interest.

\section{Acknowledgments}

This research work was financially supported by the University of the Thai Chamber of Commerce, Thailand.

\section{References}

Agoub, A.A., Smith, A.M., Giannouli, P., Richardson, R.K. and Morris, E.R. (2007). "Melt-in-the-mouth" gels from mixtures of xanthan and konjac glucomannan under acidic conditions: A rheological and calorimetric study of the mechanism of synergistic gelation. Carbohydrate Polymer, 69(4), 713-724. j.carbpol.2007.02.014

Alais, C. and Linden, G. (1991). Food Biochemistry. London: Ellis Horwood. https://doi.org/10.1007/978$1-4615-2119-8$

AOAC. (1990). Official Method of Analysis. 15th ed. Arlington, VA: Association of Official Analytical Chemists.

APHA. (2001). Compendium of Method for the Microbiological Examination of Foods. 4th ed. Washington, DC: American Public Health Association.

Anderson, M.J. and Whitcomb, P.J. (2005). RSM Simplified: Optimizing Processes Using Response
Surface Methods for Design of Experiments. New York: Productivity Press.

Bayarri, S., Izquierdo, L., Durán, L. and Costell, E. (2006). Effect of addition of sucrose and aspartame on the compression resistance of hydrocolloids gels. International Journal of Food Science and Technology, 41, 980-986. https://doi.org/10.1111/ j.1365-2621.2005.01156.x

Benmeziane, F., Djermoune-Arkoub, L., Boudraa, A.T. and Bellaagoune, S. (2018). Physicochemical characteristics and phytochemical content of jam made from melon (Cucumis melo). International Food Research Journal, 25, 133-141.

Chandrasekaran, R., Janaswamy, S. and Morris, V.J. (2003). Acetan: glucomannan interaction-A molecular modeling study. Carbohydrate Research, 338(24), 2889-2898. https://doi.org/10.1016/ j.carres.2003.08.018

Chua, M., Baldwin, T.C., Hocking, T.J. and Chan, K. (2010). Traditional uses and potential health benefits of Amorphophallus konjac K. Koch ex N.E.Br. Journal of Ethnopharmacology, 128(2), 268-278. https://doi.org/10.1016/j.jep.2010.01.021

Cochran, W.G. and Cox, G.M. (1992). Experimental Designs, 2nd ed. New York: Wiley.

Delgado-Pando, G., Cofrades, S., Rodríguez-Salas, L. and Jiménez-Colmenero, F. (2011). A healthier oil combination and konjac gel as functional ingredients in low-fat pork liver pâté. Meat Science, 88(2), 241248. https://doi.org/10.1016/j.meatsci.2010.12.028

Huang, H.-Y. and Lin, K.-W. (2004). Influence of pH and added gums on the properties of konjac flour gels. International Journal of Food Science and Technology, 39(10), 1009-1016. https:// doi.org/10.1111/j.1365-2621.2004.00881.x

Knecht, R.L. (1990). Properties of Sugar. In Pennington, N.L. and Baker, C.W. (Eds.). Sugar, p. 46-65. New York: Van Nostrand Reinhold.

Mosca, A.C., Velde, F.V., Bult, J.H.F., Boekel, M.A.J S. and Stieger, M. (2012). Effect of gel texture and sucrose spatial distribution on sweetness perception. LWT- Food Science and Technology, 46(1), 183-188. https://doi.org/10.1016/j.1wt.2011.10.009

Pavlova, V., Karakashova, L., Stamatovska, V., Delchev, N., Necinova, L., Nakov, G., Menkinoska, M. and Blazevska, T. (2013). Storage impact on the quality of raspberry and peach jams. Journal of Hygienic Engineering and Design, 5, 25-28.

Roy, M.C., Alam, M., Saeid, A., Das, B.B., Mia, M.B., Rahman, M.A., Eun, J.B. and Ahmed, M. (2018). Extraction and characterization of pectin from pomelo peel and its impact on nutritional properties 
of carrot jam during storage. Journal of Food Processing and Preservation, 42(1), e13477. https:// doi.org/10.1111/jfpp.13411

Sharma, R., Oberoi, D.P.S., Sogi, D.S. and Gill, B.S. (2009). Effect of sugar and gums on the pasting properties of cassava starch. Journal of Food Processing and Preservation, 33(3), 401-414. https://doi.org/10.1111/j.1745-4549.2008.00283.x

Sinchaipanit, P., Kerr, W.L. and Chamchan, R. (2013). Effect of sweeteners and hydrocolloids on quality attributes of reduced-calorie carrot juice. Journal of the Science of Food and Agriculture, 93(13), 33043311. https://doi.org/10.1002/jsfa.6176

Souza, V.R., Pereira, P.A.P., Pinheiro, A.C.M., Bolini, H.M.A., Borges, S.V. and Queiroz, F. (2013). Analysis of various sweeteners in low-sugar mixed fruit jam: Equivalent sweetness, time-intensity analysis and acceptance test. International Journal of Food Science and Technology, 48(7), 1541-1548. https://doi.org/10.1111/ijfs. 12123

Takigami, S. (2000). Konjac Mannan. In Phillips, G.O. and Williams, P.A. (Eds). Handbook of Hydrocolloids, p. 413-424. New York: CRC Press.

Tiwari, S. and Bhattacharya, S. (2014). Mango pulp-agar based model gel: Textural characterization. Journal of Food Science and Technology, 51(1), 75-82. https://doi.org/10.1007/s13197-011-0486-x

U-Sing Co., Ltd. (December 2012). Sucralose D-etâ. Retrieved on August 12, 2015 from Website: http:// www.det.com.eng/main.asp

Vilela, A., Matos, S., Abraão, A.S., Lemos, A.M. and Nunes, F.M. (2015). Sucrose replacement by sweeteners in strawberry, raspberry, and cherry jams: Effect on the textural characteristics and sensorial profile-A chemometric approach. Journal of Food Processing, 2015 749740. http:// dx.doi.org/10.1155/2015/749740 